\title{
STORED GRAIN PACK FACTORS FOR WHEAT: COMPARISON OF THREE METHODS TO FIELD MEASUREMENTS
}

\author{
J. M. Boac, R. Bhadra, M. E. Casada, S. A. Thompson, A. P. Turner, \\ M. D. Montross, S. G. McNeill, R. G. Maghirang
}

\begin{abstract}
Storing grain in bulk storage units results in grain packing from overbearing pressure, which increases grain bulk density and storage unit capacity. This study compared pack factors of hard red winter (HRW) wheat in vertical storage bins using different methods: the existing packing model (WPACKING), the USDA Risk Management Agency (RMA) method, and the USDA Farm Service Agency Warehouse Licensing and Examination Division (FSA-W) method. Grain bins containing HRW wheat were measured in Kansas, Oklahoma, and Texas. Packing was measured in corrugated steel bins and reinforced concrete bins with diameters ranging from 4.6 to $31.9 \mathrm{~m}$ (15.0 to $104.6 \mathrm{ft}$ ) and equivalent level grain heights ranging from 4.1 to $41.6 \mathrm{~m}$ (13.4 to $136.6 \mathrm{ft}$ ). The predicted masses of compacted stored wheat based on WPACKING, RMA, and FSA-W were compared to the reported mass from scale tickets. Pack factors predicted by WPACKING ranged from 0.929 to 1.073 for steel bins and from 0.986 to 1.077 for concrete bins. Pack factors predicted by the RMA method ranged from 0.991 to 1.157 for steel bins and from 0.993 to 1.099 for concrete bins. Pack factors predicted by the $F S A-W$ method ranged from 0.985 to 1.126 for steel bins and from 1.012 to 1.101 for concrete bins. The average absolute and median differences between the WPACKING-predicted mass and reported mass were $1.64 \%$ and $-1.26 \%$, respectively, for corrugated steel bins and $3.75 \%$ and $2.16 \%$, respectively, for concrete bins. In most cases, WPACKING underpredicted the mass in corrugated steel bins and overpredicted the mass in concrete bins. Comparison of the RMA-predicted mass and reported mass showed an average absolute difference of $4.41 \%$ with a median difference of $1.91 \%$ for $H R W$ wheat in steel bins and an average absolute difference of $3.25 \%$ with a median difference of $1.03 \%$ for concrete bins. For the FSA-W-predicted mass versus reported mass, the average absolute and median differences were $3.40 \%$ and $3.86 \%$, respectively, for steel bins and $4.34 \%$ and 3.50\%, respectively, for concrete bins. Most of the mass values were overpredicted by both the RMA and FSA-W methods. Some of the large differences observed for concrete bins can be attributed to the unique geometry of these bins and the difficulty in describing these bin shapes mathematically. Overall, compared to the reported mass, WPACKING predicted the mass of grain in the bins with less error than the current RMA and FSA-W methods. Some of the differences may be because the RMA and FSA-W methods do not include the effects of grain moisture content, bin wall type, and grain height on pack factors.
\end{abstract}

Keywords. Commercial bin measurement, Steel and concrete bins, Stored grain pack factor, Wheat, WPACKING.

Submitted for review in August 2014 as manuscript number PRS 10898; approved for publication by the Processing Systems Community of ASABE in June 2015.

Mention of trade names or commercial products in this article is solely for the purpose of providing specific information and does not imply recommendation or endorsement by the USDA. The USDA is an equal opportunity provider and employer.

The authors are Josephine M. Boac, ASABE Member, Research Associate, and Rumela Bhadra, ASABE Member, Research Associate, Department of Biological and Agricultural Engineering, Kansas State University, Manhattan, Kansas; Mark E. Casada, ASABE Member, Research Agricultural Engineer, USDA-ARS Center for Grain and Animal Health Research (CGAHR), Stored Product Insect and Engineering Research Unit (SPIERU), Manhattan, Kansas; Sidney A. Thompson, ASABE Member, Professor, College of Engineering, University of Georgia, Athens, Georgia; Aaron P. Turner, Graduate Research Assistant, and Michael D. Montross, ASABE Member, Professor, Department of Biosystems and Agricultural Engineering, University of Kentucky, Lexington, Kentucky; Samuel G. McNeill, ASABE Member, Associate Extension Professor, Department of Biosystems and Agricultural Engineering, University of Kentucky Research Center, Princeton, Kentucky; and Ronaldo G. Maghirang, ASABE Member, Professor, Department of Biological and Agricultural Engineering, Kansas State University, Manhattan, Kansas. Corresponding Author: Mark Casada, USDA-ARS CGAHR SPIERU, 1515 College Ave., Manhattan, KS 66502; phone: 785-776-2758; e-mail: mark.casada@ars.usda.gov.

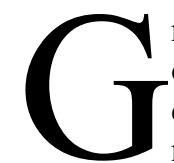
rain stored in bins is subject to packing from overburden pressure, thereby increasing its bulk density and the capacity of the storage unit and necessitating accurate pack factors to determine the mass of grain in storage. Stored grain packing or compaction is defined as the increase in grain bulk density caused by the compressibility of grain subjected to the cumulative weight of overlying material. The major variables affecting stored grain packing are grain type, moisture content, test weight, dockage, bin geometry, and bin dimensions. Because of the increase in bin storage capacity due to packing, accurate pack factor values are crucial for inventory control in the grain industry.

Multiple pack factor tables, i.e., methods of determining grain packing, are used in the grain industry for inventory control. For farm bins, the USDA Risk Management Agency (RMA) measures bins for insurance purposes, and the USDA Farm Service Agency - County Offices (FSA-C) measures bins for loan purposes. The RMA and FSA-C use the same procedure. They share an empirical pack factor table, which originated with the FSA-C and is referred to in this article as the RMA table and method. This table was 
also the basis of the current RMA loss adjustment handbook and manual (USDA, 2012a, 2012b), which provide pack factors for seven types of grain. The RMA adopted this method 10 to 15 years ago, but prior to that the RMA had a different pack factor table that is no longer used. The current method adjusts the pack factor based on test weight and the cross-sectional area of the bin. The adjusted pack factor is then applied to the measured volume of grain in the bin.

The USDA Farm Service Agency Warehouse Licensing and Examination Division (FSA-W or FSA warehouse group) is a separate federal agency that measures commercial grain storage bins for auditing purposes. Commercial grain elevators are required by law to register with an appropriate government agency if they store grain owned by others. These commercial elevators, or warehouses, can be registered with the FSA-W or with similar agencies administered by state governments. The FSA-W method is based on the Federal Warehouse Examiner's Handbook WS-3 (USDA, n.d.), which provides a detailed empirical method for estimating pack factors for six types of grain based on the initial test weight of the material and the volume per unit depth in the storage structure. The FSA-W pack factor table and calculation procedures are different from those used in the RMA method. The state agencies mentioned above generally follow the FSA-W procedures. As mentioned above, both the RMA and FSA-W methods take into account test weight for determining grain pack factors. However, neither of these methods takes into account the effects of moisture content, bin wall type, and grain height for determining pack factors.

Several studies in the literature have attempted to develop a simple and convenient method for estimating the amount of packing in grain storage structures. One of the earliest was Bates (1925), whose measurements revealed that the average amount of packing for wheat was $4.85 \%$ of the test weight. Malm and Backer (1985) measured pack factors for six crops (oats, barley, two types of sunflower, and two classes of wheat) in farm storage bins. A statistical model was tested to correlate selected physical properties to the pack factor, such as moisture content, percent dockage, test weight, grain depth, and the dimensions of the structure, but only barley and oil sunflower yielded significant terms in the model development. Malm and Backer (1985) attributed the difficulties in developing predictive models to disturbances to the grain in the commercial setting. There have been several other studies on the effects of fines and filling method on the pack factor (Chang et al., 1981, 1983; Stephens and Foster, 1976). These studies found that the grain spreaders used in commercial bins (elevator and farm) can increase packing by distributing finer particles or fines in the bins.

A science-based model for determining compaction factor, called WPACKING, was developed by Thompson et al. (1987) in an effort to simplify the procedures for estimating stored grain inventories. WPACKING employed the differential form of Janssen's (1895) equation to estimate the pressure and in-bin bulk density for a given depth of grain in a bin. Janssen's equation is commonly used in the design of storage bins and utilizes the properties of the stored material and the geometry of the storage structure to estimate in-bin pressures. The original solution of Janssen's equation assumes that the properties of the stored material (coefficient of friction $\mu$, ratio of lateral to vertical pressure $k$, and density $\rho$ ) are constant. However, by working with the differential form of the equation, the properties ( $\mu, k$, and $\rho$ ) of the stored material are allowed to vary with relevant parameters (e.g., vertical pressure). The differential form of Janssen's equation was solved with a numerical method and used to compute vertical and lateral pressures with varying depth in the bin (Ross et al., 1979). WPACKING was validated in a limited manner by Thompson et al. (1989, 1990, 1991) using data from full-size bins and flat storages and has become ASABE Standard EP413.2 for estimating the storage capacities of cylindrical grain bins (ASABE, 2010). Uniaxial compression tests were conducted for six different grains to determine the changes in bulk density at overburden pressures between 0 and $172 \mathrm{kPa}$ and moisture contents between $10 \%$ and $16 \%$ for use in WPACKING (Thompson et al., 1987; Thompson and Ross, 1983).

Quality management systems (QMS) are becoming increasingly important to grain elevator companies as specialty grain markets expand. A certified QMS is required to provide traceability, or source verification, of grains with special characteristics (Hurburgh, 2003). These systems in turn require accurate tracking and documentation of the grain handled at each facility in the supply chain. A QMS entails careful documentation throughout the process, and this documentation of the amount of grain in storage bins can be accurate only when proper pack factors are available. Inventory control is critical for stored grain managers because of financial aspects (auditing by state agencies) and for utilization of QMS to effectively track grain. The grain industry needs a reliable standard with documented accuracy to estimate the quantity of stored grain from volume measurements.

This study is part of a nationwide research project to experimentally determine the pack factors of grain in a variety of upright storage structures and conditions. The objective of this study was to compare pack factors of hard red winter (HRW) wheat in on-farm and commercial storage bins with varying bin diameter, eave height, and grain properties (i.e., moisture content and test weight) using different methods: WPACKING, the RMA method, and the FSA-W method.

\section{Field Measurements}

Data for this project were collected in 2010-2013 from storage bins containing HRW wheat in Kansas, Oklahoma, and Texas. Farmer and elevator cooperators were contacted. Those who were willing to cooperate and provide data on the grain mass and properties of their stored crops were visited, and their vertical storage bins were measured. 


\section{Data Collection}

The dimensions of the storage structures and the grain volume were measured using a laser distance meter (Disto D8, Leica Geosystems AG, St. Gallen, Switzerland). The accuracy of the integrated tilt sensor in the laser distance meter is $\pm 0.1^{\circ}$. The tilt sensor functions at any angle and at a transverse tilt of $< \pm 10^{\circ}$. If the device is held at $> \pm 10^{\circ}$, an error will occur, indicating that the device is tilted too much. The cone angle of the grain surface was determined by taking an average of seven data points evenly spaced between the bin sidewall and the top of the grain cone (if coned up) or to the bottom of the cone (if coned down). For flat surface profiles, seven data points, on average, were taken to determine the average grain height. For complex surface profiles, up to 50 surface data points were measured. These data were used to calculate the total volume of the grain inside the bin, which included the cone volume, cylinder volume, and hopper volume (if present).

In some cases, the volume of the grain was calculated using the volume per unit depth (provided by the warehouse examiner's audit sheets) as well as the laser depth profiling. Conventional measurement techniques using a tape measure with a weight tied at the end were also used to supplement the laser depth measurements and to verify the circumference of round metal bins.

In this study, grain height was defined as the height from the permanent structural floor of the bin to the point where the grain intersects the sidewall of the bin. To differentiate, the eave height was defined as the height from the permanent structural floor to the point where the bin sidewall touches the bin roof. The eave height is a fixed value irrespective of the grain volume and grain slope inside the bin. Where direct volume calculations were difficult to determine because of an irregular grain surface, CAD software (DS SolidWorks Corp., Concord, Mass.) was used along with the height and dimension data to draw the bin configuration. In some cases (e.g., hopper bottom bins), empty bin measurements were also determined, either before filling the bin or after emptying. Information such as method of filling, i.e., centered or off-centered, use of a spreader, test weight (bulk density), moisture content, and percent dockage of the incoming grain were in all cases provided by the farmers and elevator managers. Table 1 lists the parameters that were collected for each bin.

The mass of grain inside the bin and corresponding grain

Table 1. Parameters from on-site bin measurement for pack factor determination.

\begin{tabular}{lc}
\hline Parameter & Units \\
\hline Bin diameter & $\mathrm{m}(\mathrm{ft})$ \\
Eave height & $\mathrm{m}(\mathrm{ft})$ \\
Hopper bottom angle & degrees \\
Grain height (calculated from bin measurements) & $\mathrm{m}(\mathrm{ft})$ \\
Angle of repose (calculated from bin measurements) & degrees \\
Total volume of grain in bin (calculated from bin & $\mathrm{m}^{3}\left(\mathrm{ft}^{3}\right)$ \\
$\quad$ & \\
mass of grain from grain scale measurement & $\mathrm{t}(\mathrm{lb})$ \\
Method of filling the grain (fill point in the bin) & center or off-center \\
Average test weight & $\left.\mathrm{kg} \mathrm{m}^{-3}(\mathrm{lb} \mathrm{bu})^{-1}\right)$ \\
Moisture content & $\% \mathrm{w} . \mathrm{b}$. \\
Dockage amount & $\%$ \\
\hline
\end{tabular}

properties, which came from the scale tickets at the elevator, were reported by farmers after the grain was sold. For commercial bins, the mass and corresponding grain properties (i.e., test weight, moisture content, and dockage) were tracked, and the volume was measured when filling was complete and, when convenient, at intermediate points during filling. Depending on the practice of the elevator, the general methodology was adjusted to obtain accurate mass measurements and grain properties, while at the same time measuring grain volume. Thus, all values of reported mass were from elevator scale tickets and were in standard bushels (the measurement unit used in the U.S. grain industry). Each grain type has a specific mass in a standard bushel. One standard bushel of wheat weighs $60 \mathrm{lb}$, which is equivalent to $772.3 \mathrm{~kg}$ of wheat per cubic meter.

\section{Density and Packing Relationship}

The fundamental concept of grain packing is the ratio of the bulk density of the grain after packing in the bin to the initial bulk density before packing. The initial bulk density is equivalent to the grain test weight. Thus, the packing ratio is given by:

$P=\frac{D_{A}}{D_{0}}$
where $\quad D_{A}=\frac{\sum_{x=1}^{n} D_{X}}{n}$

and

$D_{A}=$ average bulk density of the grain after packing, $\mathrm{kg}$ $\mathrm{m}^{-3}\left(\mathrm{lb} \mathrm{bu}^{-1}\right)$

$D_{0}=$ initial bulk density, or uncompacted test weight, of the grain from the Winchester bushel test, $\mathrm{kg} \mathrm{m}^{-3}$ $\left(\mathrm{lb} \mathrm{bu}^{-1}\right)$

$D_{X}=$ bulk density of grain in the bin at a given depth $x$, $\mathrm{kg} \mathrm{m}^{-3}\left(\mathrm{lb} \mathrm{bu}^{-1}\right)$

$P=$ average packing ratio of the grain

$n=$ number of layers in the grain depth

$x=$ depth in the grain, $\mathrm{m}(\mathrm{ft})$.

The compaction factor is defined as the reduction in volume of the stored grain due to compaction, usually expressed as a percentage, and this term is used in ASABE Standard EP413.2 (ASABE, 2010):

$$
f_{C}=P-1
$$

where $f_{C}$ is the average compaction factor of the grain.

The mass of grain in a bin can be calculated from the measured volume of grain using:

$$
M=D_{0} \cdot P \cdot V
$$

where

$$
\begin{aligned}
& M=\text { mass of grain in the bin, } \mathrm{t}(\mathrm{lb}) \\
& V=\text { measured volume of grain in the bin, } \mathrm{m}^{3} \text { (volumetric } \\
& \mathrm{bu} \text { ). }
\end{aligned}
$$


The common grain industry term, used by both RMA and FSA-W, is pack factor $(R)$. This is also referred to as "combined test weight and pack factor" by RMA and is defined as:

$$
R=P\left(\frac{D_{0}}{D_{S}}\right)
$$

where

$R=$ pack factor including test weight

$D_{S}=$ standard bulk density (standard test weight) for a given grain type, $\mathrm{kg} \mathrm{m}^{-3}\left(\mathrm{lb} \mathrm{bu}^{-1}\right)$.

The mass of grain measured in standard bushels is then calculated as:

$$
\text { Standard } \mathrm{bu}=R \cdot V
$$

The mass of grain in $\mathrm{lb}$ is:

$$
M=D_{S} \cdot \text { Standard bu }=D_{S} \cdot R \cdot V
$$

\section{APPLICATION OF WPACKING}

Data from field measurements were used as input in WPACKING. Input variables included type of grain, grain properties (i.e., moisture content and test weight), grain height, bin diameter, type of bin wall, hopper dimensions (if applicable), and method of bin filling (resulting in a top grain surface coned upward, level, or coned downward). Based on these values, WPACKING yielded the WPACKING compaction factor $\left(f_{C, W}\right)$, the WPACKING pack factor $\left(R_{W}\right)$, and the predicted mass of the measured grain. The compaction factor $\left(f_{C, W}\right)$ and pack factor $\left(R_{W}\right)$ were determined as averages of the values calculated at specific grain depths by WPACKING using the following equations:

$$
\begin{gathered}
f_{C, X}=\left(\frac{D_{X}}{D_{0}}\right)-1 \\
f_{C, W}=\frac{\sum_{x=1}^{n} f_{C, X}}{n} \\
P_{W}=f_{C, W}+1 \\
R_{W}=P_{W}\left(\frac{D_{0}}{D_{S}}\right)
\end{gathered}
$$

where

$f_{C, X}=$ compaction factor of the grain determined by WPACKING at a given depth $x$

$f_{C, W}=$ average compaction factor of the grain determined by WPACKING

$n=$ number of depth layers used in WPACKING

$P_{W}=$ average packing ratio of the grain determined by WPACKING

$R_{W}=$ pack factor with test weight of the grain determined by WPACKING.

The total mass of grain in the bin was predicted using equation 6. Pack factors for concrete and steel bins (corrugated and smooth walled) containing HRW wheat were predicted by WPACKING. Values of the reported mass determined from scale measurements for each bin load were compared to the predicted mass from WPACKING.

\section{APPLICATION OF RMA METHOD}

The Federal Crop Insurance Corporation of the USDARMA is the primary crop insurance provider in the U.S. Its loss adjustment manual and handbook for small grains (USDA, 2012a, 2012b), which are based on an empirical approach, specify the use of pack factors for adjusting grain bin measurements based on grain test weights and bin diameters. The RMA pack factor $\left(R_{R}\right)$ is somewhat similar to the packing ratio defined above but includes the test weight measured for the bin, which was not in the definition of packing ratio. The RMA method uses conventional bin measurements and the RMA pack factor (obtained from the RMA loss adjustment manual and handbook) along with volume calculations to arrive at the final mass of grain in the bin. The RMA pack factor simplifies the calculation by eliminating the test weight adjustment step.

To compare the RMA pack factor with the other pack factor terms used in this study, the following equations were used:

$$
\begin{gathered}
f_{C, R}=P_{R}-1 \\
R_{R}=P_{R}\left(\frac{D_{0}}{D_{S}}\right)
\end{gathered}
$$

where

$$
\begin{aligned}
& f_{C, R}= \text { average compaction factor of the grain determined } \\
& \text { from RMA method } \\
& P_{R}= \text { average packing ratio of the grain determined from } \\
& \text { RMA method } \\
& R_{R}= \text { RMA pack factor from the RMA loss adjustment } \\
& \text { manual and handbook. } \\
& R_{R} \text { represents the amount of packing predicted using the }
\end{aligned}
$$
RMA method. The grain mass calculated using $R_{R}$ was compared to the reported mass in the bins based on scale measurements.

\section{ApPlication OF FSA-W Method}

The USDA Farm Service Agency warehouse (FSA-W) group uses the Federal Warehouse Examiner's Handbook WS-3 (USDA, n.d.). This handbook provides a detailed empirical method for estimating the pack factor for six varieties of grain: wheat, corn, milo, rye, soybean, and oats. This method is based on the initial test weight of the material and the volume per unit depth in the storage structure modified by an empirical correction value. The FSA-W method determines a pack factor $\left(R_{F}\right)$ that includes a test weight adjustment similar to the RMA method.

To compare the FSA-W pack factor with the other pack factor terms used in this study, the following equations were used: 


$$
\begin{gathered}
f_{C, F}=\frac{C P I}{100}-\frac{A F}{100}\left(D_{o}-D_{S}\right) \\
P_{F}=1+\frac{C P I}{100}-\frac{A F}{100}\left(D_{o}-D_{S}\right) \\
R_{F}=\left[1+\frac{C P I}{100}-\frac{A F}{100}\left(D_{o}-D_{S}\right)\right]\left(\frac{D_{o}}{D_{S}}\right)
\end{gathered}
$$

where

$C P I=$ converted packing index from the Federal Warehouse Examiner's Handbook WS-3

$A F=$ FSA-W method adjustment factor

$f_{C, F}=$ average compaction factor of the grain determined from FSA-W method

$P_{F}=$ average packing ratio of the grain determined from FSA-W method

$R_{F}=$ FSA-W method pack factor.

The grain mass calculated using $R_{F}$ was compared to the reported mass in the bins based on scale measurements.

\section{RESUlTS AND DiscusSiON \\ FIELD MEASUREMENTS}

Table 2 shows the measured storage bin and grain characteristics for HRW wheat in steel bins in Kansas and Oklahoma. All of the steel bins were corrugated steel. The bin diameters ranged from 4.6 to $31.9 \mathrm{~m}(15.0$ to $104.6 \mathrm{ft}$ ) with equivalent level grain heights of 4.1 to $25.6 \mathrm{~m}$ (13.4 to $84.1 \mathrm{ft}$ ).

The measured cone angle for HRW wheat in the steel bins ranged from $18.0^{\circ}$ to $38.6^{\circ}$ with a mean of $24.5^{\circ}$. For grain loaded through a single center spout, the cone angle would be expected to match the angle of repose (AoR) of the grain for filling. The same applies to inverted cone angles; if the grain remains undisturbed, the cone angle should match the AoR of the grain for emptying. Other loading methods, especially grain spreaders, and anything that disturbs the surface after loading can change the cone angle so that it does not match the AoR. The literature shows that the AoR for wheat at different moisture contents ranges from $16.0^{\circ}$ to $41.0^{\circ}$ for filling or piling and from $23.8^{\circ}$ to $45.5^{\circ}$ for emptying or funneling (Stahl, 1950; Lorenzen, 1957, 1959; Mohsenin, 1986; MWPS, 1987; Molenda and Horabik, 2005). The measured cone angles in the steel bins in this study are within the range of published AoR values for filling. The wide range in the measured cone angles $\left(18.0^{\circ}\right.$ to $\left.38.6^{\circ}\right)$ was likely due to the wide variability in all factors affecting cone angles in the field. Ten of the steel bins monitored in this study had flat bottoms, while six bins had hopper bottoms. The mean hopper bottom angle was $34.1^{\circ}$, and it ranged from $27.4^{\circ}$ to $38.0^{\circ}$. Some steel bins were loaded off-center, i.e., the peak of the cone was offset from the center of the bin (table 2). The HRW wheat in steel bins had an average test weight of $767.7 \mathrm{~kg} \mathrm{~m}^{-3}\left(59.6 \mathrm{lb} \mathrm{bu}^{-1}\right)$ [standard deviation $(\mathrm{SD})=$ $29.3 \mathrm{~kg} \mathrm{~m}^{-3}\left(2.3 \mathrm{lb} \mathrm{bu}^{-1}\right)$ ], average moisture content of $11.6 \%$ (w.b.) $(\mathrm{SD}=0.8 \%$ ), and average dockage of $0.57 \%$ $(\mathrm{SD}=0.24 \%)$.

The range of the WPACKING pack factor $\left(R_{W}\right)$ was 0.929 to 1.073 with a mean of $1.036(\mathrm{SD}=0.036)$. The RMA pack factor $\left(R_{R}\right)$ range was higher at 0.991 to 1.157 . The mean RMA pack factor was also the highest at 1.087 $(\mathrm{SD}=0.049)$. The FSA-W pack factor $\left(R_{F}\right)$ range was between the other two methods ( 0.985 to 1.126$)$ with a mean of $1.082(\mathrm{SD}=0.037)$.

Table 3 shows the measured storage bin and grain characteristics for HRW wheat in concrete bins in Kansas, Oklahoma, and Texas. The diameter of the bins ranged from 4.6 to $10.3 \mathrm{~m}$ ( 15 to $33.7 \mathrm{ft}$ ) with equivalent level grain heights ranging from 5.5 to $41.6 \mathrm{~m}$ (17.9 to $136.6 \mathrm{ft})$. As is typical of concrete bins at commercial elevators, these bins

\begin{tabular}{|c|c|c|c|c|c|c|c|c|c|c|c|c|}
\hline Location & $\begin{array}{c}\text { Bin } \\
\text { Shape }\end{array}$ & $\begin{array}{c}\text { Bin } \\
\text { Bottom }\end{array}$ & $\begin{array}{c}\text { Bin } \\
\text { Wall }\end{array}$ & $\begin{array}{l}\text { Filling } \\
\text { Method }\end{array}$ & $\begin{array}{c}\text { Average } \\
\text { Moisture } \\
\text { Content } \\
\text { (\% w.b.) } \\
\end{array}$ & $\begin{array}{c}\text { Average } \\
\text { Test } \\
\text { Weight } \\
\left(\mathrm{kg} \mathrm{m}^{-3}\right) \\
\end{array}$ & $\begin{array}{c}\text { Average } \\
\text { Dockage } \\
(\%) \\
\end{array}$ & $\begin{array}{c}\text { Equivalent } \\
\text { Diameter } \\
(\mathrm{m}) \\
\end{array}$ & $\begin{array}{c}\text { Equivalent } \\
\text { Level } \\
\text { Height } \\
\text { (m) }\end{array}$ & $\begin{array}{c}\text { WPACKING } \\
\text { Pack } \\
\text { Factor, } \\
R_{W} \\
\end{array}$ & $\begin{array}{c}\text { RMA } \\
\text { Pack } \\
\text { Factor, } \\
R_{R} \\
\end{array}$ & $\begin{array}{c}\text { FSA-W } \\
\text { Pack } \\
\text { Factor, } \\
R_{F} \\
\end{array}$ \\
\hline Kansas & Round & Flat & Corrugated & Off-center & 12.3 & 784.2 & 0.44 & 4.6 & 6.3 & 1.050 & 1.048 & 1.068 \\
\hline Kansas & Round & Flat & Corrugated & Off-center & 10.6 & 790.1 & 0.20 & 4.6 & 6.4 & 1.057 & 1.054 & 1.075 \\
\hline Kansas & Round & Flat & Corrugated & Off-center & 11.6 & 772.8 & 0.47 & 7.3 & 5.4 & 1.034 & 1.051 & 1.079 \\
\hline Kansas & Round & Flat & Corrugated & Off-center & 10.2 & 732.9 & 0.53 & 5.5 & 4.1 & 0.978 & 0.991 & 1.015 \\
\hline Kansas & Round & Flat & Corrugated & Center & 11.4 & 803.0 & 0.41 & 9.1 & 4.9 & 1.073 & 1.099 & 1.126 \\
\hline Kansas & Round & Flat & Corrugated & Center & 13.1 & 785.1 & 0.89 & 16.5 & 7.0 & 1.057 & 1.157 & 1.115 \\
\hline Kansas & Round & Flat & Corrugated & Center & 11.8 & 780.8 & 0.24 & 12.8 & 8.5 & 1.052 & 1.125 & 1.110 \\
\hline Kansas & Round & Flat & Corrugated & Center & 11.4 & 780.8 & 0.96 & 23.9 & 13.3 & 1.058 & 1.152 & 1.110 \\
\hline Kansas & Round & Flat & Corrugated & Center & 11.8 & 780.4 & 0.92 & 23.9 & 20.0 & 1.064 & 1.152 & 1.110 \\
\hline Kansas & Round & Flat & Corrugated & Center & 12.9 & 764.2 & 0.33 & 14.4 & 25.6 & 1.048 & 1.105 & 1.090 \\
\hline Kansas & Round & Hopper & Corrugated & Off-center & 11.1 & 769.4 & 0.57 & 9.1 & 6.6 & 1.032 & 1.062 & 1.087 \\
\hline Kansas & Round & Hopper & Corrugated & Center & 11.7 & 781.1 & 0.79 & 9.1 & 6.0 & 1.047 & 1.075 & 1.100 \\
\hline Kansas & Round & Hopper & Corrugated & Center & 12.0 & 759.3 & 0.64 & 31.9 & 22.5 & 1.040 & 1.126 & 1.084 \\
\hline Kansas & Round & Hopper & Corrugated & Off-center & 11.9 & 774.9 & 0.38 & 9.1 & 6.2 & 1.039 & 1.068 & 1.093 \\
\hline Oklahoma & Round & Hopper & Corrugated & Center & 10.7 & 678.1 & 0.60 & 27.3 & 24.0 & 0.929 & 1.021 & 0.985 \\
\hline Oklahoma & Round & Hopper & Corrugated & Center & 10.6 & 745.8 & 0.70 & 27.3 & 21.6 & 1.016 & 1.107 & 1.068 \\
\hline \multicolumn{2}{|c|}{ Minimum } & & & & 10.2 & 678.1 & 0.20 & 4.6 & 4.1 & 0.929 & 0.991 & 0.985 \\
\hline \multicolumn{2}{|c|}{ Maximum } & & & & 13.1 & 803.0 & 0.96 & 31.9 & 25.6 & 1.073 & 1.157 & 1.126 \\
\hline \multicolumn{2}{|c|}{ Mean } & & & & 11.6 & 767.7 & 0.57 & 14.8 & 11.8 & 1.036 & 1.087 & 1.082 \\
\hline \multicolumn{2}{|c|}{ SD } & & & & 0.8 & 29.3 & 0.24 & 9.1 & 8.0 & 0.036 & 0.049 & 0.037 \\
\hline \multicolumn{2}{|c|}{ Median } & & & & 11.6 & 777.7 & 0.55 & 11.0 & 6.8 & 1.048 & 1.087 & 1.089 \\
\hline
\end{tabular}
were tall and narrow. The tallest grain height was $41.6 \mathrm{~m}$

Table 2. Summary of bin characteristics and HRW wheat properties for the measured round corrugated steel bins. 
Table 3. Summary of bin characteristics and HRW wheat properties for the measured concrete bins.

\begin{tabular}{|c|c|c|c|c|c|c|c|c|c|c|c|c|}
\hline Row & Location & $\begin{array}{c}\text { Bin } \\
\text { Shape }\end{array}$ & $\begin{array}{c}\text { Bin } \\
\text { Bottom }\end{array}$ & $\begin{array}{l}\text { Filling } \\
\text { Method }\end{array}$ & $\begin{array}{c}\text { Average } \\
\text { Moisture } \\
\text { Content } \\
\text { (\% w.b.) }\end{array}$ & $\begin{array}{c}\text { Average } \\
\text { Test } \\
\text { Weight } \\
\left(\mathrm{kg} \mathrm{m}^{-3}\right)\end{array}$ & $\begin{array}{c}\text { Average } \\
\text { Dockage } \\
(\%)\end{array}$ & $\begin{array}{c}\text { Equivalent } \\
\text { Diameter } \\
(\mathrm{m})\end{array}$ & $\begin{array}{c}\text { Equivalent } \\
\text { Level } \\
\text { Height } \\
\text { (m) }\end{array}$ & $\begin{array}{c}\text { WPACKING } \\
\text { Pack } \\
\text { Factor, } \\
R_{W} \\
\end{array}$ & $\begin{array}{c}\text { RMA } \\
\text { Pack } \\
\text { Factor, } \\
R_{R}\end{array}$ & $\begin{array}{c}\text { FSA-W } \\
\text { Pack } \\
\text { Factor, } \\
R_{F} \\
\end{array}$ \\
\hline 8 & Kansas & Round & Hopper & Off-center & 11.9 & 739.0 & 0.39 & 5.5 & 27.9 & 1.000 & 0.998 & 1.022 \\
\hline 7 & Kansas & Round & Hopper ${ }^{[a]}$ & Off-center & 11.5 & 737.4 & 0.39 & 4.6 & 22.7 & 0.994 & 0.996 & 1.015 \\
\hline 56 & Kansas & Round & Hopper $^{[a]}$ & Center & 12.5 & 772.3 & n.a. & 4.6 & 20.8 & 1.041 & 1.035 & 1.055 \\
\hline 38 & Oklahoma & Hexagon & Hopper & Center & 12.0 & 796.8 & 0.40 & 4.8 & 41.6 & 1.076 & 1.062 & 1.083 \\
\hline 39 & Oklahoma & Hexagon & Hopper & Center & 12.2 & 792.9 & 0.50 & 4.8 & 39.6 & 1.071 & 1.057 & 1.078 \\
\hline 40 & Oklahoma & Hexagon & Hopper & Center & 11.8 & 798.1 & 0.70 & 4.8 & 30.3 & 1.076 & 1.063 & 1.084 \\
\hline 44 & Oklahoma & Hexagon & Hopper & Center & 10.4 & 799.3 & 0.60 & 4.8 & 41.4 & 1.077 & 1.064 & 1.085 \\
\hline 45 & Oklahoma & Hexagon & Hopper & Center & 10.1 & 785.2 & 0.70 & 4.8 & 41.1 & 1.057 & 1.049 & 1.070 \\
\hline 32 & Oklahoma & Hexagon & Hopper $^{[a]}$ & Center & 12.0 & 786.5 & 0.40 & 4.8 & 8.4 & 1.054 & 1.050 & 1.071 \\
\hline 33 & Oklahoma & Hexagon & Hopper $^{[\mathrm{a}]}$ & Center & 11.6 & 781.3 & 0.30 & 4.8 & 27.3 & 1.053 & 1.046 & 1.065 \\
\hline 34 & Oklahoma & Hexagon & Hopper $^{[a]}$ & Center & 11.6 & 786.5 & 0.40 & 4.8 & 39.5 & 1.061 & 1.050 & 1.071 \\
\hline 35 & Oklahoma & Hexagon & Hopper $^{[a]}$ & Center & 11.7 & 798.1 & 0.50 & 4.8 & 34.4 & 1.076 & 1.063 & 1.084 \\
\hline 36 & Oklahoma & Hexagon & Hopper $^{[a]}$ & Center & 11.5 & 773.6 & 0.50 & 4.8 & 34.0 & 1.044 & 1.036 & 1.056 \\
\hline 37 & Oklahoma & Hexagon & Hopper $^{[a]}$ & Center & 10.0 & 783.9 & 0.60 & 4.8 & 39.9 & 1.056 & 1.048 & 1.068 \\
\hline 41 & Oklahoma & Hexagon & Hopper $^{[a]}$ & Center & 11.3 & 780.0 & 0.60 & 4.8 & 29.6 & 1.052 & 1.043 & 1.064 \\
\hline 42 & Oklahoma & Hexagon & Hopper $^{[a]}$ & Center & 11.8 & 795.5 & 0.60 & 4.8 & 39.8 & 1.073 & 1.060 & 1.081 \\
\hline 43 & Oklahoma & Hexagon & Hopper $^{[a]}$ & Center & 11.3 & 774.9 & 0.70 & 4.8 & 40.0 & 1.046 & 1.038 & 1.058 \\
\hline 46 & Oklahoma & Hexagon & Hopper $^{[a]}$ & Center & 10.0 & 792.9 & 0.80 & 4.8 & 36.9 & 1.067 & 1.057 & 1.078 \\
\hline 29 & Oklahoma $^{[\mathrm{b}]}$ & Hexagon & Hopper & Center & 11.8 & 760.7 & 0.60 & 4.8 & 25.9 & 1.026 & 1.022 & 1.042 \\
\hline 30 & Oklahoma $^{[\mathrm{b}]}$ & Hexagon & Hopper & Center & 11.0 & 759.4 & 0.50 & 4.8 & 12.2 & 1.020 & 1.021 & 1.040 \\
\hline 31 & Oklahoma $^{[\mathrm{b}]}$ & Hexagon & Hopper & Center & 11.6 & 749.1 & 1.60 & 4.8 & 5.5 & 1.001 & 1.009 & 1.029 \\
\hline 22 & Oklahoma $^{[\mathrm{b}]}$ & Hexagon & Hopper $^{[\mathrm{a}]}$ & Center & 11.3 & 763.3 & 0.60 & 4.8 & 38.0 & 1.030 & 1.028 & 1.045 \\
\hline 23 & Oklahoma $^{[\mathrm{b}]}$ & Hexagon & Hopper $^{[a]}$ & Center & 11.2 & 753.0 & 0.80 & 4.8 & 10.1 & 1.010 & 1.014 & 1.033 \\
\hline 24 & Oklahoma $^{[\mathrm{b}]}$ & Hexagon & Hopper $^{[a]}$ & Center & 11.5 & 755.6 & 0.90 & 4.8 & 10.1 & 1.014 & 1.017 & 1.036 \\
\hline 25 & Oklahoma $^{[\mathrm{b}]}$ & Hexagon & Hopper $^{[a]}$ & Center & 11.7 & 759.4 & 0.60 & 4.8 & 13.8 & 1.022 & 1.021 & 1.040 \\
\hline 26 & Oklahoma $^{[\mathrm{b}]}$ & Hexagon & Hopper $^{[\mathrm{a}]}$ & Center & 11.6 & 783.9 & 0.80 & 4.8 & 11.6 & 1.052 & 1.048 & 1.068 \\
\hline 27 & Oklahoma $^{[\mathrm{b}]}$ & Hexagon & Hopper $^{[a]}$ & Center & 11.1 & 746.6 & 0.70 & 4.8 & 13.9 & 1.004 & 1.006 & 1.026 \\
\hline 28 & Oklahoma $^{[\mathrm{b}]}$ & Hexagon & Hopper $^{[a]}$ & Center & 11.4 & 735.0 & 1.00 & 4.8 & 9.3 & 0.986 & 0.993 & 1.012 \\
\hline 54 & Texas & Round & Hopper & Center & 11.5 & 774.5 & 0.80 & 10.3 & 39.5 & 1.055 & 1.099 & 1.101 \\
\hline 55 & Texas & Interstice & Hopper & Center & 11.3 & 774.2 & 0.78 & 5.1 & 37.6 & 1.045 & 1.037 & 1.060 \\
\hline 57 & Texas & Hexagon & Hopper & Center & 11.3 & 767.4 & 0.68 & 5.2 & 36.0 & 1.037 & 1.030 & 1.052 \\
\hline 58 & Texas & Hexagon & Hopper & Center & 11.4 & 768.7 & 0.60 & 5.2 & 33.9 & 1.038 & 1.031 & 1.054 \\
\hline 59 & Texas & Hexagon & Hopper & Off-center & 11.6 & 771.8 & 0.89 & 5.2 & 36.7 & 1.043 & 1.034 & 1.057 \\
\hline 60 & Texas & Hexagon & Hopper & Center & 11.7 & 763.8 & 0.64 & 5.2 & 35.6 & 1.032 & 1.026 & 1.048 \\
\hline 61 & Texas & Hexagon & Hopper & Center & 12.5 & 743.2 & 0.76 & 5.2 & 13.1 & 1.002 & 1.002 & 1.025 \\
\hline \multicolumn{2}{|c|}{ Minimum } & & & & 10.0 & 735.0 & 0.30 & 4.6 & 5.5 & 0.986 & 0.993 & 1.012 \\
\hline \multicolumn{2}{|c|}{ Maximum } & & & & 12.5 & 799.3 & 1.60 & 10.3 & 41.6 & 1.077 & 1.099 & 1.101 \\
\hline \multicolumn{2}{|r|}{ Mean } & & & & 11.5 & 771.5 & 0.66 & 5.0 & 28.0 & 1.040 & 1.036 & 1.056 \\
\hline \multicolumn{2}{|r|}{$\mathrm{SD}$} & & & & 0.6 & 18.9 & 0.24 & 0.9 & 12.2 & 0.026 & 0.023 & 0.022 \\
\hline \multicolumn{2}{|r|}{ Median } & & & & 11.5 & 773.6 & 0.60 & 4.8 & 33.9 & 1.044 & 1.036 & 1.057 \\
\hline
\end{tabular}

a] Side-discharge hopper bottom bins.

[b] These bins were measured from a benchmark point, indicating that they were not empty.

$(136.6 \mathrm{ft})$, which was higher than that of any of the steel bins measured ( $25.6 \mathrm{~m}$ or $84.1 \mathrm{ft})$.

The measured cone angle for HRW wheat in concrete bins ranged from $1.8^{\circ}$ to $45.1^{\circ}$ with a mean of $22.2^{\circ}$. Most of the cone angles ( 25 out of 35 ) for HRW wheat were within the range of AoR found in the literature for filling $\left(16.0^{\circ}\right.$ to $\left.41.0^{\circ}\right)$ and for emptying $\left(23.8^{\circ}\right.$ to $45.5^{\circ}$ ) (Stahl, 1950; Lorenzen, 1957, 1959; Mohsenin, 1986; MWPS, 1987; Molenda and Horabik, 2005). The angles of highly disturbed surface profiles ranged from $1.8^{\circ}$ to $9.6^{\circ}$; however, slightly disturbed surface profiles (with values smaller than the true AoR) are often not apparent during visual inspection.

All concrete bins had hopper bottoms with either center or side discharge. The center-discharge hopper bottom bins had right conic hoppers with horizontal discharge openings, while the side-discharge hopper bottom bins had oblique conic hoppers with vertical discharge openings. The mean hopper bottom angle was $35.4^{\circ}$ and ranged from $33.8^{\circ}$ to $47.3^{\circ}$. The hopper bottom angles for the concrete bins were higher than those of the steel bins $\left(27.4^{\circ}\right.$ to $\left.38.0^{\circ}\right)$. Except for a few cases, most of the bins were center-filled. The grain characteristics were similar to those found in the steel bins with a mean test weight of $771.5 \mathrm{~kg} \mathrm{~m}^{-3}\left(59.9 \mathrm{lb} \mathrm{bu}^{-1}\right)$ $\left[\mathrm{SD}=18.9 \mathrm{~kg} \mathrm{~m}^{-3}\left(1.5 \mathrm{lb} \mathrm{bu}^{-1}\right)\right]$, mean moisture content of $11.5 \%$ (w.b.) ( $\mathrm{SD}=0.6 \%$ ), and mean dockage of $0.66 \%$ $(\mathrm{SD}=0.24 \%)$. None of the measured concrete bins used spreaders during filling. In most cases, the cross-section of the bin was circular. However, in the concrete bins located in Oklahoma and some in Texas, the cross-section was a regular hexagon. In calculating the capacity of the bin using WPACKING, the equivalent diameters were used for these non-circular bins.

The WPACKING pack factors $\left(R_{W}\right)$ for concrete bins were slightly higher than those for steel bins, ranging from 0.986 to 1.077 with a mean of $1.040(\mathrm{SD}=0.026)$. However, the RMA pack factor $\left(R_{R}\right)$ for concrete bins was slightly lower with a mean of $1.036(\mathrm{SD}=0.023)$ and ranged from 0.993 to 1.099 . The FSA-W pack factor $\left(R_{F}\right)$ range was higher than the other two methods (1.012 to 1.101$)$ with a mean of $1.056(\mathrm{SD}=0.022)$.

\section{COMPARISON OF METHODS FOR BINS}

Figure 1 shows the difference between the reported mass 


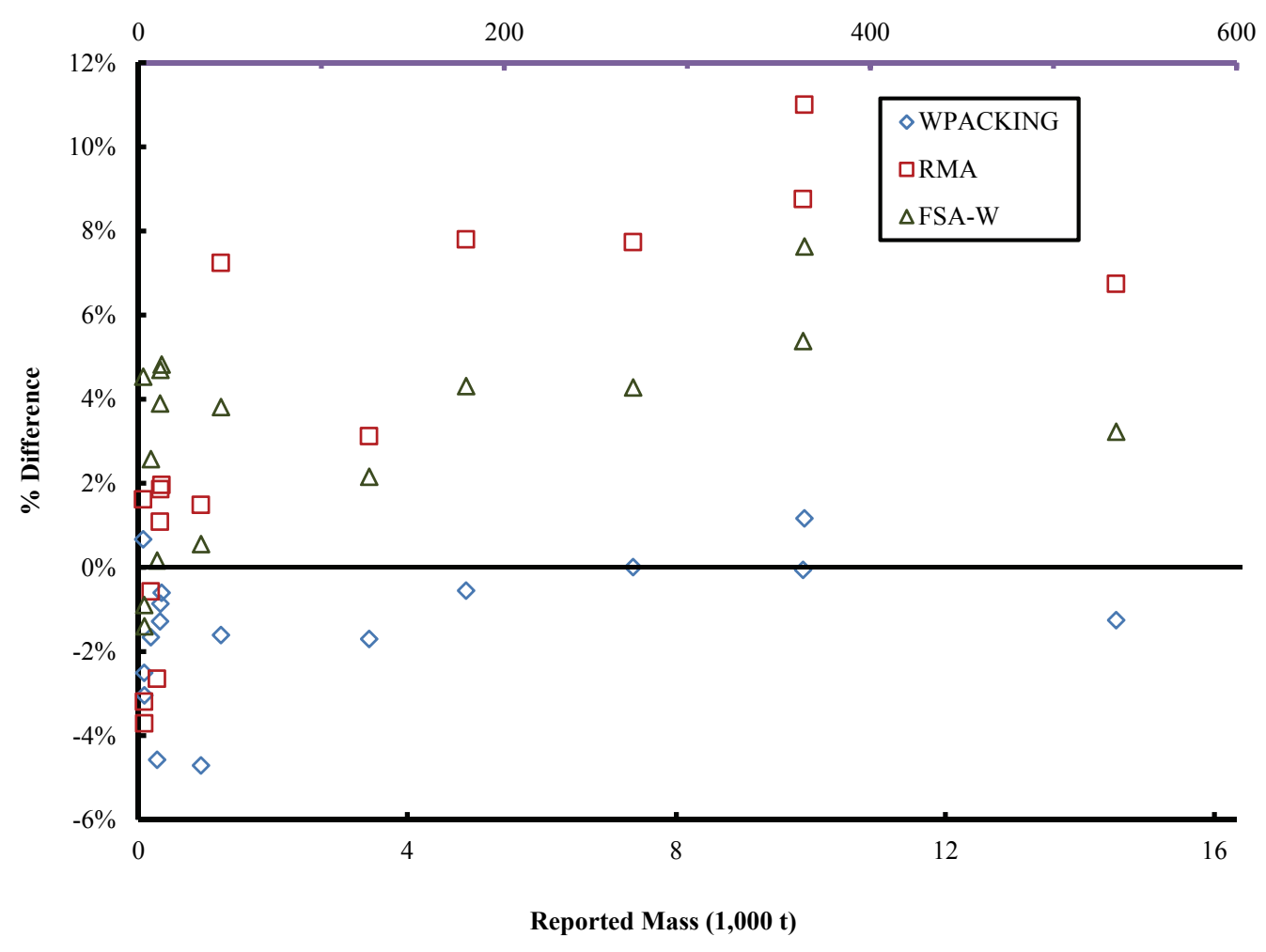

Figure 1. Percent differences between reported mass and predicted mass from each method (WPACKING, RMA, and FSA-W) for HRW wheat in corrugated steel bins.

from scale measurements and the predicted mass from WPACKING, RMA, and FSA-W for corrugated steel bins. The range of differences between the reported mass and the predicted mass by WPACKING was $-4.70 \%$ to $1.17 \%$ with a median difference of $-1.26 \%$, indicating that WPACKING was underpredicting by $1.26 \%$ compared to the reported mass. The median value of the differences does not indicate the magnitude of the differences but measures the overall bias of the method. There were only three cases of overprediction by WPACKING, two flat-bottom and one hopper-bottom steel bins. The WPACKING-predicted mass for the large steel bins was always within $-2.00 \%$ of the reported mass.

The difference between the reported mass and the RMA-predicted mass for steel bins ranged from $-3.71 \%$ to $11.0 \%$ (fig. 1). The median was $1.91 \%$, which indicated that the RMA method was overpredicting by $1.91 \%$ compared to the reported mass. The median difference was higher than for WPACKING (-1.26\%). Seventy-five percent of the measured steel bins were overpredicted by the RMA method.

The range of the differences between the FSA-Wpredicted mass and the reported mass was $-1.40 \%$ to $7.63 \%$, of which two out of 16 steel bins were overpredicted compared to the reported mass (fig. 1). The median difference was $3.86 \%$, which was higher than the median differences for WPACKING (-1.26\%) and RMA (1.91\%).

Figures 2, 3, and 4 plot the reported mass for steel bins and the predicted mass from WPACKING, the RMA method, and the FSA-W method against a 1:1 line. These figures illustrate that WPACKING predicted the reported mass more closely than the other two methods.

Figure 5 shows a comparison of the differences between the reported mass and the mass predicted by WPACKING, RMA, and FSA-W for reinforced concrete bins. The range of differences between the reported mass and the WPACKING-predicted mass for concrete bins was $-5.89 \%$ to $9.74 \%$, which is higher than the range for steel bins. Measurement of concrete bins is often difficult due to their construction with tall and narrow bin shapes. However, the median difference was $2.16 \%$, with the majority of the bins (23 out of 35) overpredicted by WPACKING.

The range of differences between the RMA-predicted mass and the reported mass for concrete bins was $-7.19 \%$ to $7.75 \%$ (fig. 5). The median difference was $1.03 \%$, which was lower than WPACKING (2.16\%). Most of the data for concrete bins (21 out of 35) were overpredicted.

The range of differences between the FSA-W-predicted mass and the reported mass was $-4.70 \%$ to $10.43 \%$, and 30 out of 35 bins were overpredicted (fig. 5). The median difference was $3.50 \%$, which was higher than the median differences for WPACKING (2.16\%) and RMA (1.03\%).

The reported mass and the predicted mass from WPACKING, the RMA method, and the FSA-W method for concrete bins are plotted against a 1:1 line in figures 6 , 7 , and 8 , illustrating that WPACKING predicted the report- 


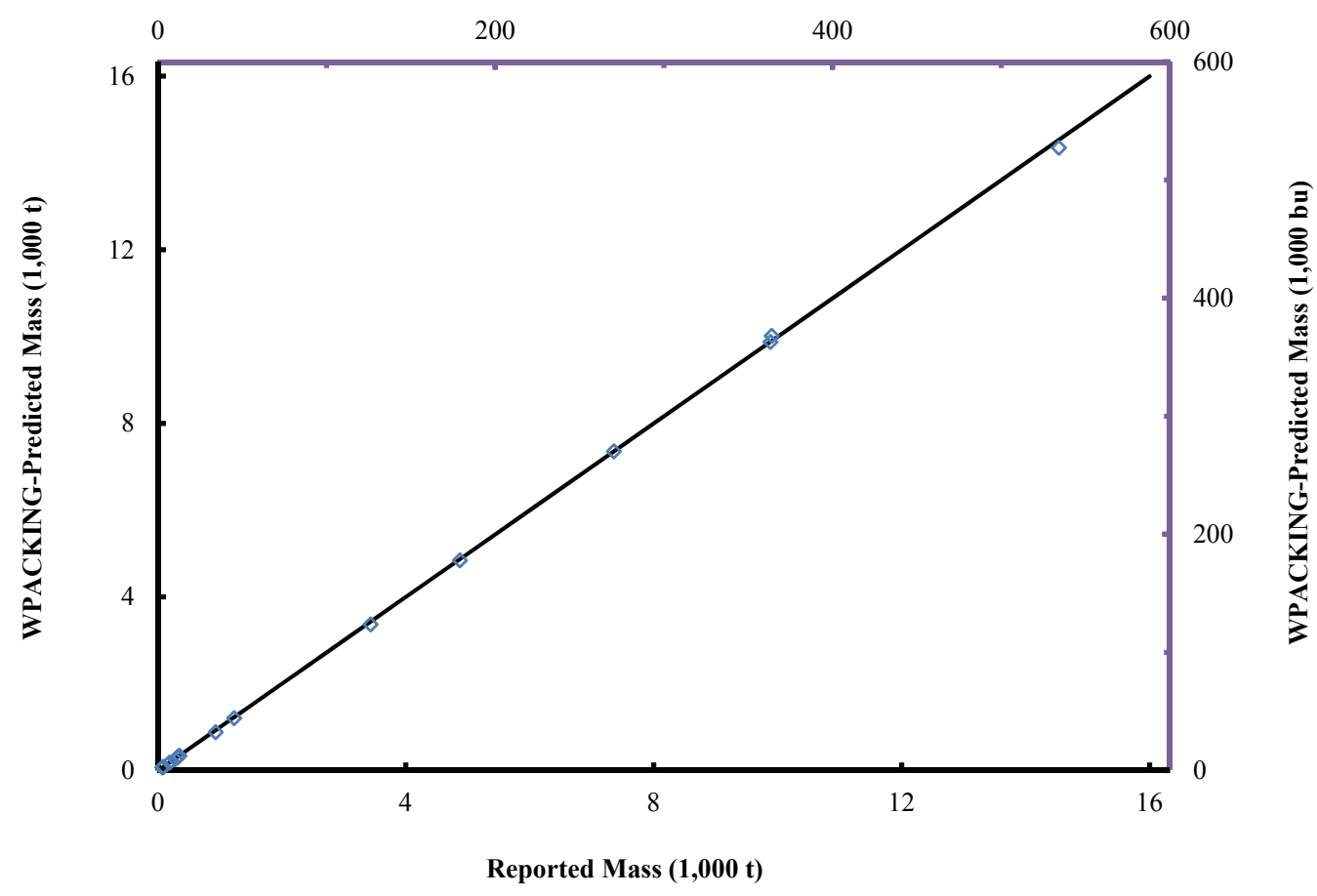

Figure 2. WPACKING-predicted mass plotted against reported mass for HRW wheat in corrugated steel bins.

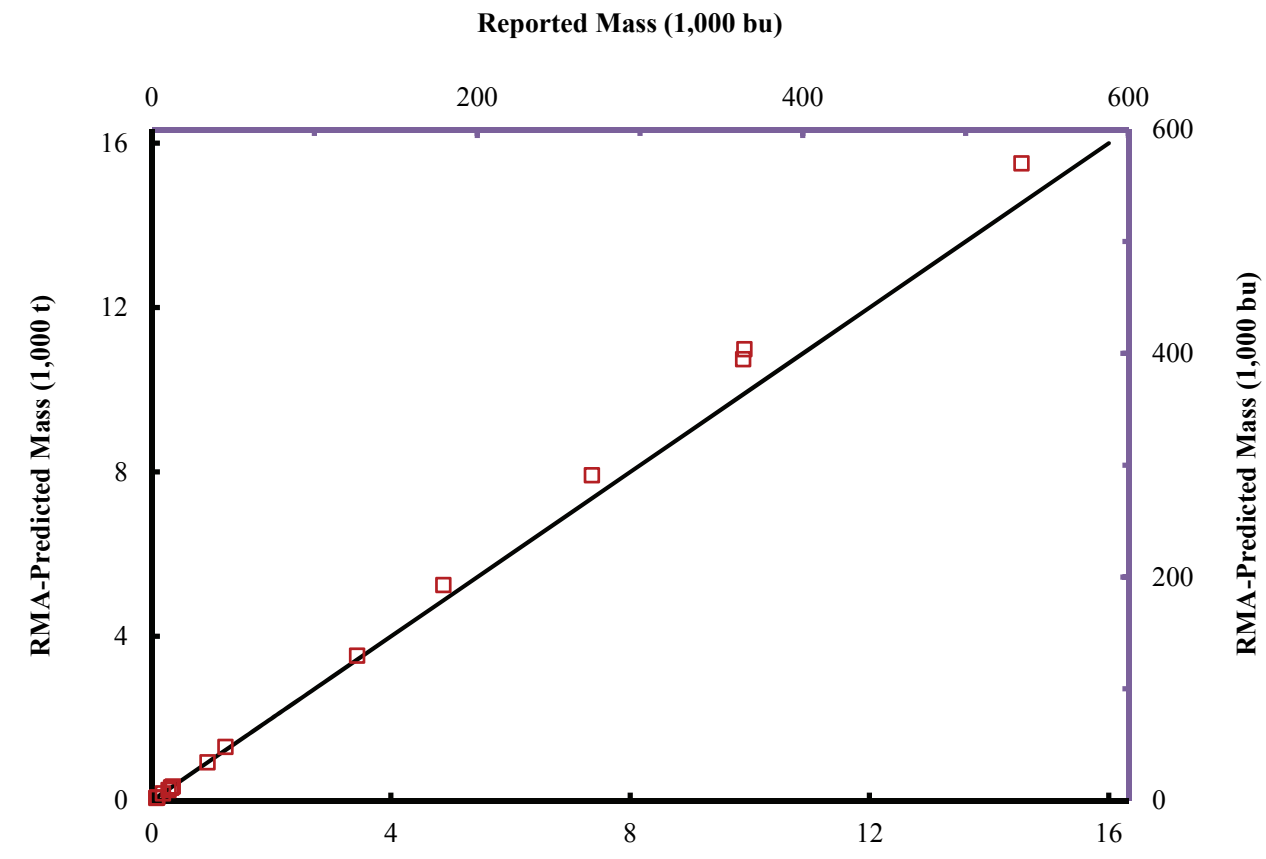

Reported Mass (1,000 t)

Figure 3. RMA-predicted mass plotted against reported mass for HRW wheat in corrugated steel bins.

ed mass more closely than the other two methods.

For WPACKING, the average absolute difference between predicted and measured mass for steel bins (1.64\%) was less than the differences for RMA (4.41\%) and FSA-W $(3.40 \%)$. The average absolute difference is defined as the average of the absolute values of the differences between predicted and reported mass, which measures the average 


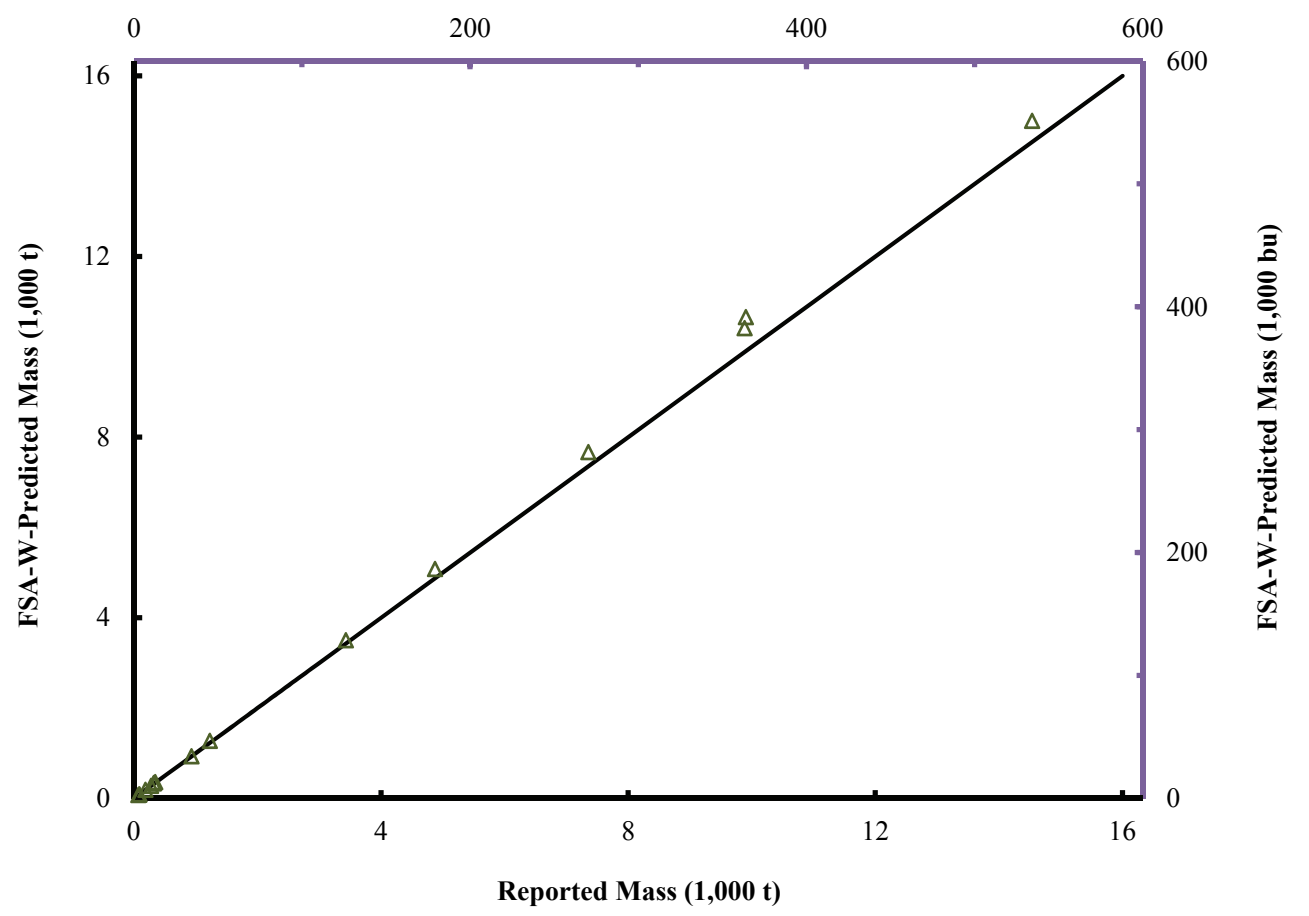

Figure 4. FSA-W-predicted mass plotted against reported mass for HRW wheat in corrugated steel bins.

magnitude of the deviations without the direction of the difference. For steel bins, paired t-tests indicated that the average absolute difference for WPACKING was significantly different from the average absolute differences for RMA $(p=0.015)$ and FSA-W $(p=0.047)$. The average absolute differences for RMA and FSA-W were not significantly different from each other $(p=0.156)$. For concrete bins, paired t-tests also indicated that the average absolute difference for WPACKING (3.75\%) was significantly different from those for the RMA (3.25\%) and FSA-W $(4.34 \%)$ methods ( $p<0.01$ in both cases), and the average absolute differences for RMA and FSA-W were also significantly different from each other $(p<0.01)$. In general, these results indicate that WPACKING predicted the mass for HRW wheat with more accuracy than the RMA and FSA-W methods.

Overall, figures 1 and 5 indicate that the percent difference range for HRW wheat in concrete bins $(-5.89 \%$ to $9.74 \%)$ is greater than for HRW wheat in steel bins $(-4.70 \%$ to $1.17 \%$ ) from WPACKING. This could be because WPACKING was mainly developed using input values generated from steel bins (ASABE, 2010). The data in figures 1 and 5 also indicate that the WPACKING predictions could be improved by calibrating WPACKING. Calibrating WPACKING may mean improving and/or adjusting the current compressibility relationship in the model for HRW wheat. The current values are based on bin design values and not values measured within bins during storage. Adjustment in WPACKING can also include getting more accurate values for $k$ and $\mu$ by fine-tuning within the limits of regression analyses or by using data in the literature where the pressures in bins have been measured. Using these measured pressure values, a more accurate value of $k$ and $\mu$ might be obtained.

The RMA-predicted mass values deviated further from the measured mass in the steel bins compared to the WPACKING predictions. The reason for the RMA method deviations is not clear since the source of those pack factors is unknown. For larger steel bins $(\geq 23.9 \mathrm{~m}$ or $78.3 \mathrm{ft}$ in diameter), the RMA-predicted mass was very different (6.75\% to $11.0 \%$ difference) from the reported mass of grain in the bin. In addition, the effect of bin wall type is not considered in the RMA method. Bin wall type and material could affect the coefficient of friction and lateral to vertical pressure inputs, as stated in Janssen's (1895) model. However, for concrete bins, the RMA-predicted mass was closer to the reported mass than the values from WPACKING. The FSA-W method showed less error than the RMA method in predicting mass values for steel bins, but not for concrete bins.

Regarding all three prediction methods (WPACKING, RMA, and FSA-W), any error in the volume measurement propagates through the prediction of mass. For example, a grain height difference of $2.5 \mathrm{~cm}$ would change the predicted mass of grain by $3400 \mathrm{~kg}(0.07 \%)$, and a height difference of $5 \mathrm{~cm}$ would change the predicted mass by $0.21 \%$. Thus, some of the errors in the predicted mass calculations can be attributed to volume measurement errors. These measurement errors should be random errors that do not affect the overall assessment of errors in the three prediction methods. 
Reported Mass (1,000 bu)

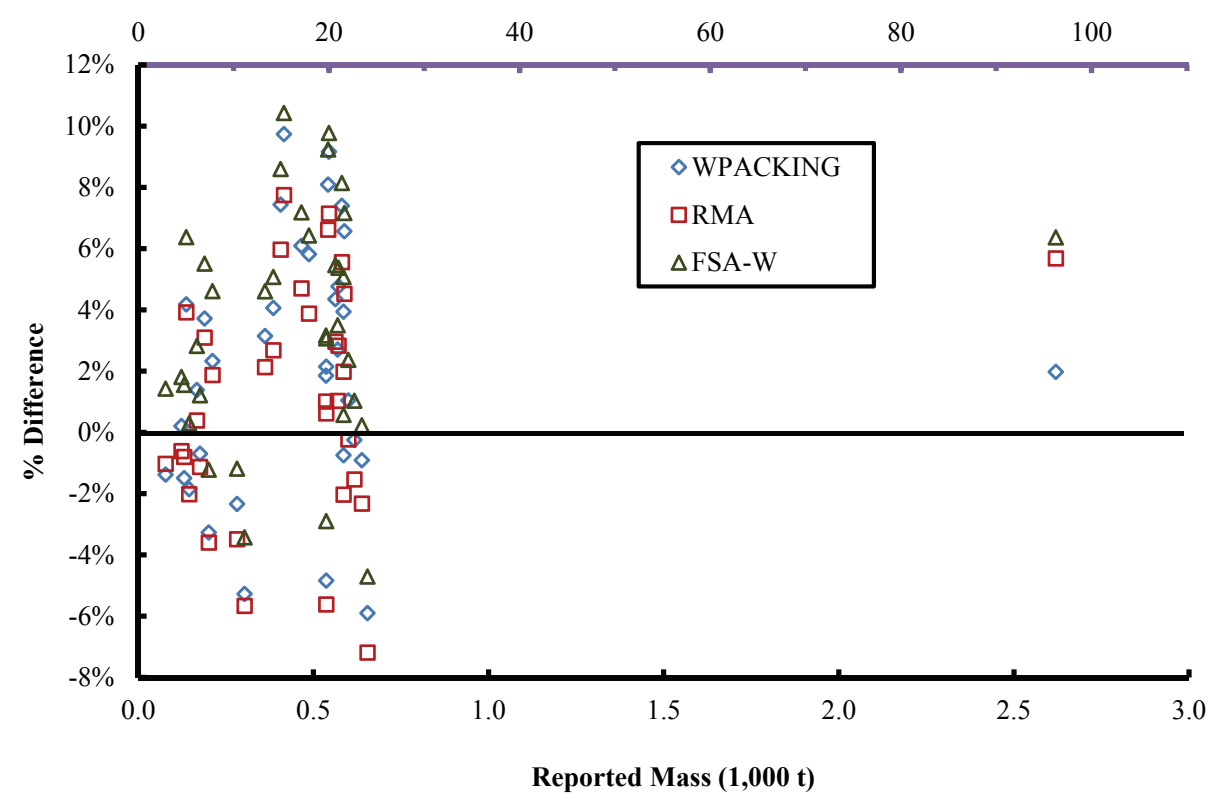

(a) All bins.

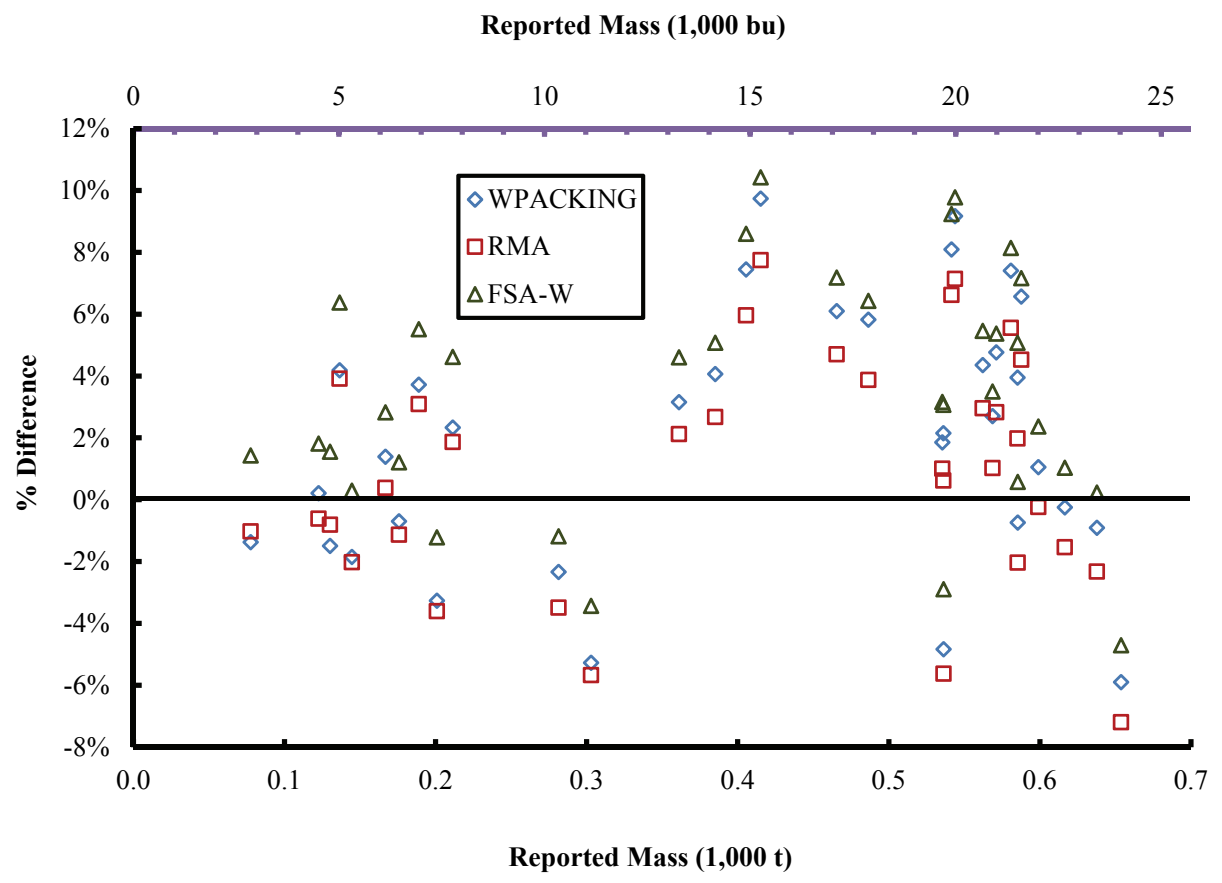

(b) Bins of less than $700 \mathrm{t}(35,000 \mathrm{bu})$ capacity.

Figure 5. Percent difference between reported mass and predicted mass from each method (WPACKING, RMA, and FSA-W) for HRW wheat in reinforced concrete bins.

\section{SUMMARY AND CONCLUSIONS}

Commercial and on-farm vertical storage bins made of concrete and corrugated steel, with varying bin diameter, eave height, and grain properties, were measured in Kansas, Oklahoma, and Texas to determine the pack factor of hard red winter wheat. Bin diameters ranged from 4.6 to $31.9 \mathrm{~m}$ (15.0 to $104.6 \mathrm{ft}$ ) for steel bins and from 4.6 to $10.3 \mathrm{~m}$ (15 to $33.7 \mathrm{ft}$ ) for concrete bins. Equivalent level grain heights ranged from 4.1 to $25.6 \mathrm{~m}$ (13.4 to $84.1 \mathrm{ft}$ ) for steel bins and from 5.5 to $41.6 \mathrm{~m}$ (17.9 to $136.6 \mathrm{ft}$ ) for concrete bins. These bins consisted of flat bottom, regular hopper bottom, and side-discharge hopper bottom bins. The WPACKING, RMA, and FSA-W pack factors were calculated for all measured bins and used to predict the mass of grain in the bin, which was compared to the reported mass of grain. The pack factors included both the packing and test weight effects on the grain. The reported mass was 


\section{Reported Mass (1,000 bu)}

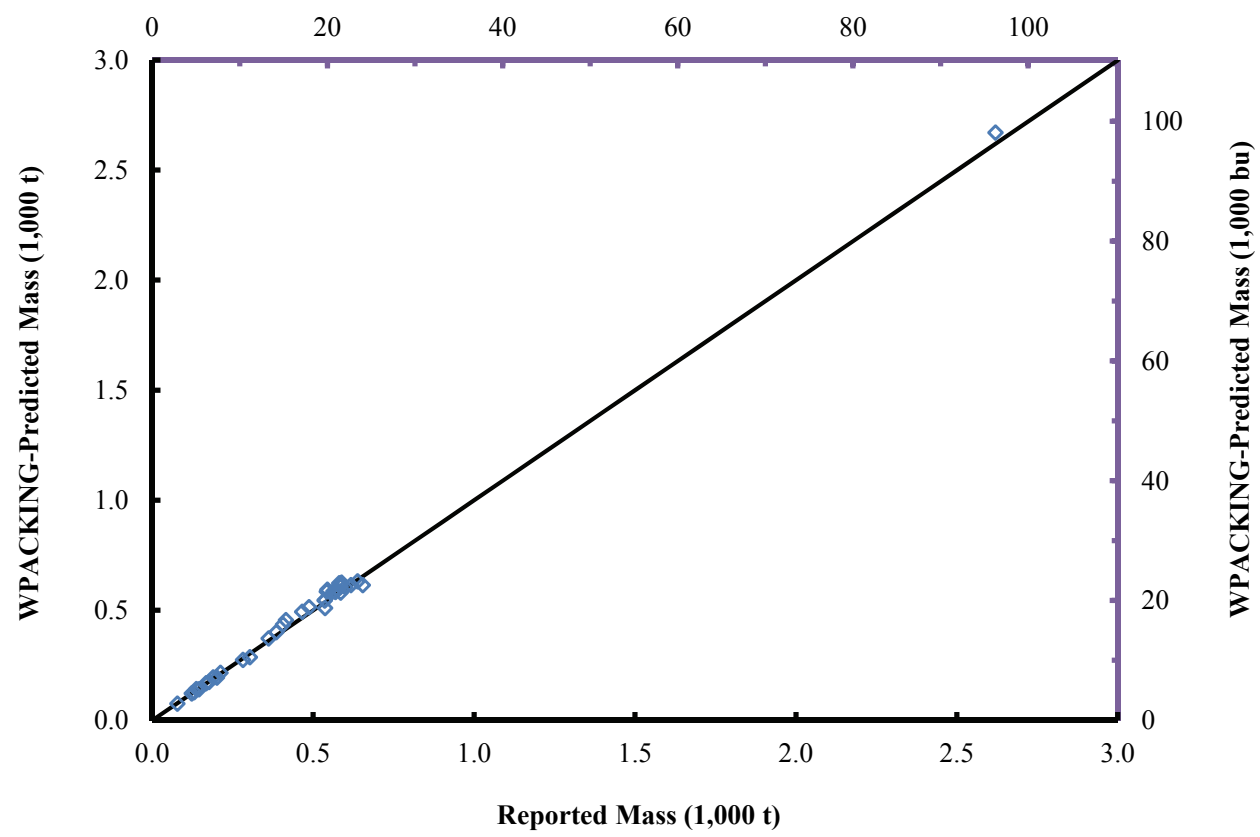

Figure 6. WPACKING-predicted mass plotted against reported mass for HRW wheat in reinforced concrete bins.

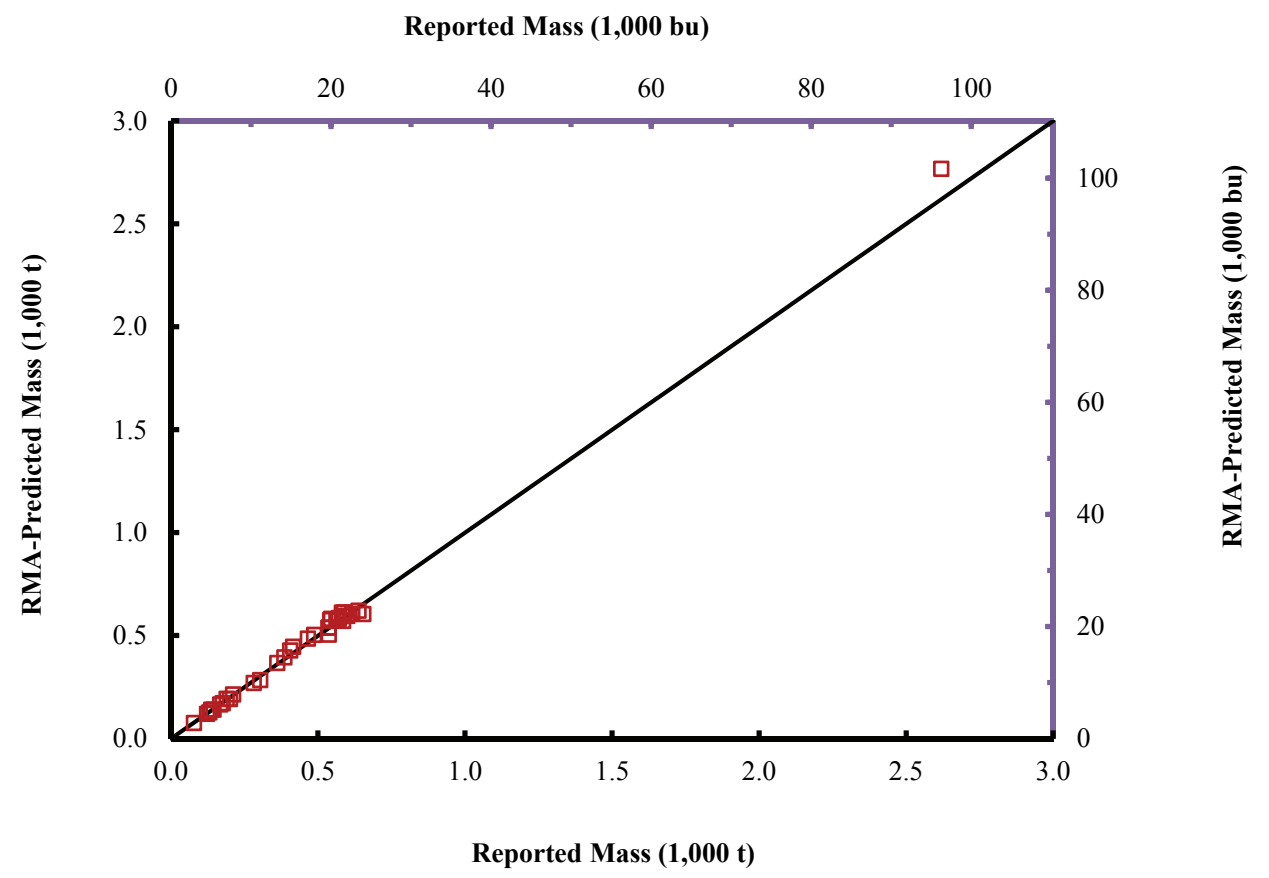

Figure 7. RMA-predicted mass plotted against reported mass for HRW wheat in reinforced concrete bins.

determined from scale tickets provided by the operator. The major findings were:

- Pack factors predicted by WPACKING ranged from 0.929 to 1.073 for steel bins and from 0.986 to 1.077 for concrete bins. Pack factors predicted by the RMA method ranged from 0.991 to 1.157 for steel bins and from 0.993 to 1.099 for concrete bins. Pack factors predicted by the FSA-W method ranged from 0.985 to 1.126 for steel bins and from 1.012 to 1.101 for concrete bins.

- For the corrugated steel bins, the average absolute difference between the WPACKING-predicted mass and the reported mass was $1.64 \%$ with a median difference of $-1.26 \%$. In most of the bins (13 out of 16), WPACKING underpredicted the grain mass. The average absolute difference for the RMA method (4.41\%) was higher than for WPACKING (1.64\%) and the FSA-W method (3.40\%). Most of the steel 


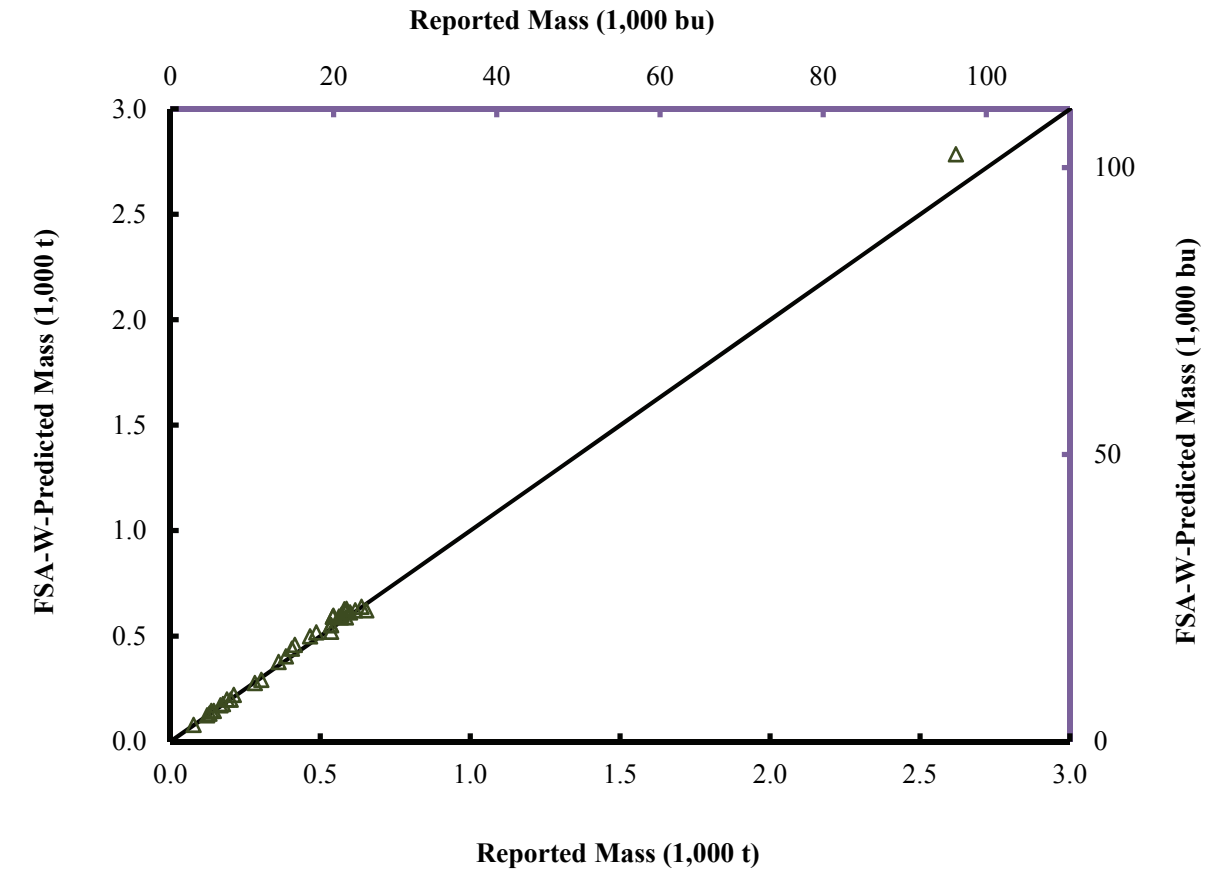

Figure 8. FSA-W-predicted mass plotted against reported mass for HRW wheat in reinforced concrete bins.

bins were overpredicted by the RMA (12 out of 16) and FSA-W (14 out of 16) methods.

- For the reinforced concrete bins, the average absolute difference between the WPACKING-predicted mass and the reported mass was $3.75 \%$. WPACKING slightly overpredicted the mass of grain in these bins. The average absolute difference for the RMA method $(3.25 \%)$ was slightly lower than for WPACKING $(3.75 \%)$ and much lower than for FSA-W (4.34\%). The median difference for WPACKING was also much higher for concrete bins $(2.16 \%)$ than for the steel bins (-1.26\%). In most cases, all three methods overpredicted the reported mass values. Some of the large differences in this case can be attributed to the unique geometry of these bins and the difficulty in describing these bin shapes mathematically.

- Overall, compared to the reported mass, WPACKING predicted the mass of grain in the bins with less error than the current RMA and FSA-W methods. Some of the differences may be because the RMA and FSA-W methods do not include the effects of grain moisture content, bin wall type, and grain height on pack factors.

\section{ACKNOWLEDGEMENTS}

The research was supported by the USDA (CRIS No. 5430-43440-007-08R) and by the Kansas Agricultural Experiment Station (Contribution No. 15-158-J). The assistance provided by Dr. Dennis Tilley (USDA-ARS CGAHR), Dr. Ekramul Haque (KSU), Kevin Hamm (KSU), Chris Weston (USDA-ARS CGAHR), and Howell Gonzales (KSU) in conducting the field tests is highly appreciated.

We want to thank Dalton Henry (Kansas Wheat Commission), Dr. Tom Herald (USDA-ARS CGAHR), Brian
Linin and Richard Bauman (Frontier Ag, Inc.), Marvin Schlatter (ADM), Dr. Danny Rogers, (KSU), Greg Mclure (Riley County Extension Office), Mike Schulte (Oklahoma Wheat Commission), Ben Boerner (Texas Grain \& Feed Association), Ned Bergman and Steve Becker (Farm Service Agency), and Dr. Charles R. Hurburgh Jr. (Iowa State University), and other extension specialists, university professors, and grain researchers for assistance in locating cooperators.

We would like thank our farmer cooperators with HRW wheat bins who participated in this project: Steve Clanton, Jay Cook, Terry Kastens (Kastens, Inc.), Brent Linin, Roger May (May Family Farms), Bruce Otte (in memoriam), Lee and Margaret Scheufler (Scheufler Farms, Inc), David Schemm, and Alan Townsend.

We also would like to thank our elevator cooperators with HRW wheat bins: Brandon Channel (St. Mary's Farmers Union Coop), Joey Meibergen and Montie Walton (W.B. Johnston Terminal Elevator); Joshua Dechant (Frontier Ag, Inc.); Lindsey Bowers and Steven Craig (United Agricultural Cooperative, Inc.), Scott Day and Jimmie Bradley (Attebury Grain LLC), and Gary Holcomb and Dave Hoffman of (Sunray Coop).

Additional thanks are due to Ned Bergman (Kansas City Commodity Office, Warehouse Licensing and Examination Division, USDA-FSA) and Tim Oyler (Product Administration and Standards Division, USDA-RMA) for providing information on the history and current application of pack factor methods.

\section{REFERENCES}

ASABE. (2010). EP413.2: Procedure for establishing volumetric capacities of cylindrical bins. St. Joseph, Mich.: ASABE. 
Bates, E. N. (1925). Estimating the quantity of grain in bins. Misc. Circular No. 41. Washington, D.C.: USDA.

Chang, C. S., Shackelford, L. E., Lai, F. S., Martin, C. R., \& Miller, B. S. (1981). Bulk properties of corn as affect by multiple-point grain spreaders. Trans. ASAE, 26(6), 1632-1636. http://dx.doi.org/10.13031/2013.34504.

Chang, C. S., Converse, H. H., \& Martin, C. R. (1983). Bulk properties of grain as affect by self-propelled rotational type grain spreaders. Trans. ASAE, 26(5), 1543-1550. http://dx.doi.org/10.13031/2013.34167.

Hurburgh, C. R. (2003). Certification and source verification in the grain-handling industry. Paper presented at the Symposium on Product Differentiation and Market Segmentation in Grain and Oilseeds: Implications for Industry in Transition. Washington, D.C.: USDA Economic Research Service. Retrieved from http://lib.dr.iastate.edu/cgi/viewcontent.cgi?article=1363\& conte $\mathrm{xt}=$ abe eng_conf.

Janssen, H. A. (1895). Versuche über getreidedruck in silozellen. Zeitschrift d. Vereines Deutscher Ingenieure, 39(35), 10451049.

Lorenzen, R. T. (1957). Effect of moisture content on mechanical properties of small grains. MS thesis. Davis, California: University of California-Davis.

Lorenzen, R. T. (1959). Moisture effect on friction coefficients of small grain. ASAE Paper No. 59416. St. Joseph, Mich.: ASAE.

Malm, J. K., \& Backer, L. F. (1985). Compaction factors for six crops. Trans. ASAE, 28(5), 1634-1636. http://dx.doi.org/10.13031/2013.32489.

Mohsenin, N. N. (1986). Physical Properties of Plant and Animal Materials. New York, N.Y.: Gordon and Breach Science.

Molenda, M., \& Horabik, J. (2005). Part 1. Characterization of mechanical properties of particulate solids for storage and handling. In J. Horabik, \& K. Laskowski (Eds.), Mechanical Properties of Granular Agro-Materials and Food Powders for Industrial Practice. Lublin, Poland: Institute of Agrophysics Polish Academy of Sciences.

MWPS. (1987). Storage. In Grain Drying, Handling and Storage Handbook (MWPS-13) (2 ed.). Ames, Iowa: MidWest Plan Service.
Ross, I. J., Bridges, T. C., Loewer, O. J., \& Walker, J. N. (1979). Grain bin loads as affected by grain moisture content and vertical pressure. Trans. ASAE, 22(3), 592-597. http://dx.doi.org/10.13031/2013.35068.

Stahl, B. M. (1950). Grain bin requirements. Circular 835. Washington, D. C.: USDA.

Stephens, L. E., \& Foster, G. H. (1976). Grain bulk properties as affected by mechanical grain spreader. Trans. ASAE, 19(2), 358363. http://dx.doi.org/10.13031/2013.36027.

Thompson, S. A., \& Ross, I. J. (1983). Compressibility and frictional properties coefficients of wheat. Trans. ASAE, 26(4), 1171-1176, 1180. http://dx.doi.org/10.13031/2013.34099.

Thompson, S. A., McNeill, S. G., Ross, I. J., \& Bridges, T. C. (1987). Packing factors of whole grains in storage structures. Appl. Eng. Agric., 3(2), 215-221. http://dx.doi.org/10.13031/2013.26677.

Thompson, S. A., McNeill, S. G., Ross, I. J., \& Bridges, T. C. (1990). Computer model for predicting the packing factors of whole grains in flat storage structures. Appl. Eng. Agric., 6(4), 465-470. http://dx.doi.org/10.13031/2013.26415.

Thompson, S. A., Schwab, C. V., \& Ross, I. J. (1989). Packing of whole grains in full-sized bins. ASAE Paper No. 894547. St. Joseph, Mich.: ASAE.

Thompson, S. A., Schwab, C. V., \& Ross, I. J. (1991). Calibration of a model for packing whole grains. Appl. Eng. Agric., 7(4), 450-456. http://dx.doi.org/10.13031/2013.26244.

USDA. (n.d.). Federal Warehouse Examiner's Handbook: Grain Pack Data WS-3. Washington, D.C.: USDA Agricultural Stabilization and Conservation Service, Warehouse Division (Now USDA, Farm Service Agency, Commodity Services, Procurement and Warehouse Branch).

USDA. (2012a). Loss Adjustment Manual (LAM) Standards Handbook: Directive No. 25010-1H. Washington, D.C.: USDA Risk Management Agency. Retrieved from www.rma.usda.gov/data/25000/2012.html.

USDA. (2012b). Small Grains Loss Adjustment Standards Handbook: Directive No. 25430-1H. Washington, D.C.: USDA Risk Management Agency. Retrieved from www.rma.usda.gov/data/25000/2012.html. 